\title{
The Role of Culture and Arts in Peace Building and Reconciliation
}

\author{
Dorothy Goredema \\ Midlands State University, Zimbabwe \\ goredemad@msu.ac.zw
}

\section{Abstract}

This paper argues that conflict resolution, peace building and reconciliation in the $21^{\text {st }}$ century requires a cultural slant in addition to conventional political and military approaches. This development should not be surprising especially given the nature of recent wars which have turned out to be more intra-state than inter-state. Since the end of the Cold war, wars have been focused on issues of culture, ethnicity, politics and religion than on nationalisms. Thus, cultural beliefs, norms, traditions, ethnicity and religion have contributed towards many major disruptions that have cost innocent lives and loss of valuable property. In addition, conflicts and divisions within societies reflect lack of appreciation and intolerance of others' cultural beliefs, views and are motivated by cultural differences. In the wars of recent decades, rape has been used as a weapon of war and children have been abducted to be killers and sex-slaves. Millions of families have been uprooted from their homes. Taken as a whole, these current developments allow us to witness how everyday people are experiencing the historical, cultural, economic and social forces that shape our world. As such, this present effort unpacks the role that culture can play in peace building and reconciliation. The research is qualitative in nature and applied discourse analysis to draw information from journal articles, published books as well as reports in the area of reconciliation and peace-building. Examples will be drawn mainly from Zimbabwe and other different countries in world to substantiate some of the arguments put forward in the paper.

Key Words: Culture, Traditions, Arts, Conflict Resolution, Peace building and Reconciliation.

\section{Introduction}

A ccording to Shah (2014), Post-Cold War Africa has suffered spates of conflict, violence, insecurity and destruction of property. By 1990-2008 not less than twentyeight sub-Saharan African states had experienced conflict (Shah, 2014). These include Algeria, Angola, Burundi, Democratic Republic of Congo, Cote d'Ivoire, Eritrea and 
Ethiopia, Guinea-Bissau, Kenya, Liberia, Nigeria, Rwanda, Sierra Leone, Somalia, Sudan, South Sudan, Uganda and Zimbabwe. The Human Security Report (2005 p. 4) observed that between 1990-2009, many Africans were killed in Africa`s wars than the rest of the world combined.

Several studies attribute Africa`s violent conflicts to the failure of its political elite to accept democratic principles of accountability, equity, justice and the rule of law (Human Rights Security Report, 2005 p. 4). Furthermore, most violent conflicts in Africa have been traced to contested bases of unresolved economic grievances, greedy, corruption and prolonged rule by those leaders who are in power. In addition, dictatorship, alienation, poverty, unemployment illiteracy, infrastructural decay constitutes the root causes of Africa`s conflicts.

Years of bad governance in countries like Angola, Sierra Leone and Liberia, endemic corruption and the denial of basic human rights created deplorable conditions that made conflict inevitable. In addition, it is now a fact that ethnicity kills in Africa. Thus, some of the wars witnessed in African states like Rwanda, Darfur, and Liberia were basically tribal conflicts fought between competing tribal groups. A few years after independence, Zimbabwe was engulfed in ethnic-based clashes and inter-nationalist power struggles in the Midlands and Matebeleland provinces from 1983-1987. In Darfur, conflict and violence was rampant between the light skinned Arabs versus the Black Africans. In Nigeria, the Bakassi Boys were involved in an ethnic riot in which three hundred northern Nigerian migrants were slaughtered. Political opponents were also abducted prior to the 2003 elections (Meagher 2007).

Religious factors, especially the intra-Islamic dimension of the African conflicts should also be taken note of in countries like Rwanda and Nigeria. In Nigeria, Falola (1998 pp. 2-3) observed that politicians urged their followers to vote along religious lines. Muslims are told to vote for Muslims, and Christians for Christians. In Africa, elections have rarely been peaceful. Belonging to different political formations has provoked hatred, conflicts and violence resulting in a lot of bloodshed and destruction of property. Kenya and Côte d'Ivoire are good examples where electoral violence rocked the countries to unprecedented levels in 2007 and 2008 respectively. In Kenya, following the 2007 presidential election, large areas of the country exploded in conflict and violence between different ethnic groups as most people viewed it as a stolen vote when President Mwai Kibaki won over Raila Odinga, the violence that followed was mostly described in apolitical terms and as "ethnic hatreds" (Fjelde, 2009).

In many African states, the unemployed and underemployed youths have embarked on a range of violent activities in search for better livelihoods. This situation has exacerbated instances of thuggery, assassinations, militancy and ethnic massacres. In the case of Islam, some impoverished youths have gravitated into religious fundamentals with networks stretching across Africa and Saudi Arabia (Meagher 2004). All these violent conflicts reflect the impact of severe economic stress and state negligence on dynamic local institutions. Resultantly, people are perceived in terms of their ethnicity, religion and social classes. Added to this, the citizen question connects with these forces in 
conflict-prone areas. Thus, Africa has emerged from these violent episodes divided, further impoverished and its citizenry violated, dehumanized, fearful, scarred, wounded emotionally, spiritually and physically.

It is within this backdrop that the study argues that in the current context of post-Cold War relations, the "toolkit" used for conflict resolution, peace building and reconciliation needs to be vastly expanded and improved to include tools from a range of related disciplines in order to successfully address and deal with conflict in the $21^{\text {st }}$ century.

In Africa, conflict resolution, peace building and reconciliation requires a cultural slant in addition to conventional political approaches given that cultural beliefs, norms, traditions, ethnicity and religion have contributed towards many conflicts and violence. Peace building and reconciliation processes can be guided by old guidelines as well as time-proven traditions; which attend to the emotional, psychological and spiritual aspects of violence on both the victims and the perpetrators. State-centric approaches (presidential pardons, amnesties, clement orders and a national policy of reconciliation among other approaches) whilst necessary, lack the capacity to attend to the history, cultural nuances, wounds and deeply seated perceptions of victims.

\section{Conceptualizing Culture, Reconciliation and Peace Building}

According to Lederach (2003), peace building refers to a series of interventions that are designed to address the root causes of conflict and to prevent the start or resumption of the conflict. This can only be achieved through sustainable peace. The former United Nations Secretary-General, Boutros Boutros Ghali (1992) is of the view that the concept of peace building is a long-term process, which aims to address underlying social, economic and political causes of conflict. Peace building is based on the premise that sustainable peace must be built on strong social, cultural, economic, and political foundations that serve the needs of the populace. Therefore, peace building involves strategic, prioritized interventions whose objective is to deal with the drivers and consequences of conflict. Furthermore, peace building seeks to create incentives for non-violent behavior, reduce direct violence, transform relationships and ultimately to strengthen the capacity of institutions to support and consolidate the peace.

Peace building acknowledges the multi-faceted nature of violence that is direct, cultural and structural violence (Galtung, 1996 p.12). From this conceptualization, peace building exists along the conflict continuum to ensure that it has an impact on various levels such as the socio-economic, political, cultural, psychological and environmental dimensions. In essence, peace building consists of a wide range of activities, including capacity building, reconciliation, and societal transformation, advocacy, development initiatives as well as addressing immediate livelihood needs (Ibid). In his works on peace building, Lederach (2003) emphasizes the need for complementarity in any peace building process. He stresses the multilayered approach to peace, implying that many actors such as the government and its ministries and departments, traditional leaders, faith based organizations, artist and civil society organizations among others have 
significant roles to play at various levels in pursuing and consolidating peace (Lederach, 1997 p.63).

Reconciliation is a critical aspect of peace building, which addresses the social, psychological and emotional dimensions of peace through confronting the past. The term reconciliation is frequently used by scholars and practitioners to refer to processes and strategies that are used to deal with fractured relationships or to address a society's violent past. Kriesberg (2004) conceptualizes reconciliation as transformative, meaning, it involves changing destructive and negative attitudes, beliefs, narratives and behaviors into positive as well as constructive ones thereby promoting peace. Evidence of this transformation is often reflected in the capacity of people to co-exist, dialogue and forgive each other. In addition, reconciliation often involves deliberate processes of personal contact, sustained interaction and dialogue among members of the community. Dimensions of reconciliation processes are varied, and these include restoration, forgiveness and repair of broken trust as well as mending of the social fabric.

Like peace building, reconciliation also occurs at various levels, i.e. the individual, interpersonal or collective levels. On the one hand, reconciliation at individual level often involves people choosing to reconcile with themselves or with others (whether privately or publicly). Collective reconciliation often involves social groups or communities choosing to participate in reconciliation processes and initiatives with others. The national level of reconciliation involves more public processes, which are often guided and supported by key national actors such as the government participating in International or national peace days, community peace days or peace gatherings. Reconciliation at any level requires stakeholders to lend support and legitimacy towards the reconciliation initiatives and programs.

The engagement of leaders in processes such as national dialogues, public apologies, public ceremonies, and memorialization initiatives is therefore imperative. This helps especially in creating space for both individual and community level processes of reconciliation. More often than not, individual and collective reconciliation are closely linked (Mark, 2007 p. 24). Individual reconciliation is a critical building block for collective reconciliation, while public processes of reconciliation also influence the way individuals reconcile with each other. Reconciliation should be context-driven, and must pay attention to the expressed needs of the population, the dynamics, history cultural nuances, traditional values, indigenous approaches; beliefs and history of the people concerned, the conflict as well as the local capacities to engage in reconciliation (Murithi, 2006 p.34).

In this article, the term 'culture' is the complete range of behaviors, traditions and beliefs of any group of people who trace a long history of living together. And by arts, I am referring to music, painting, poetry, prose, song, dance, film and photography. Reconciliatory elements in different cultures such as religion can be harnessed to promote peace. The central themes of religions such as Islam, Christianity, Hinduism and the African traditional religion is peace, tolerance and societal harmony. In most 
Southern African countries, the traditional concept of "ubuntu" (a Nguni word describing an African philosophy of life, i.e. understanding the interconnected of all beings and seeing the universe as one organic entity), is used in conflict prevention and resolution efforts (Tutu, 1995).

Ubuntu calls for the respect of each other's humanity and needs. It seeks the contentment of the whole community not just some individuals, and expounds a conciliatory as well as non-adversarial dispute resolution process where understanding is the goal, not vengeance. Thus, communities and leaders can actually appeal to conflicting parties to have Ubuntu, to cease fighting and consider the humanness of the other. Even forgiveness is considered as an aspect of Ubuntu for the good of the whole community. In this way, the African culture is a culture that encourages peaceful co-existence and the elements of the culture can be used whenever peace is threatened. From this angle, culture forms our belief systems, shapes our perceptions, understanding and guides our behavior. This is similar to the restorative justice valued by Eastern religions and cultures in which forgiveness and empathy is championed as opposed to the retributive justice of revenge and vengeance. Within this backdrop, one can see that indeed culture has got a significant role to play in peace building and reconciliation.

For Zimbabwe, the arts and culture can be a powerful catalyst in bringing about peace building and reconciliation within the hearts of individuals as well as between communities; changing who we are and how we relate to each other. Cultural dances, gatherings, ceremonies and performances are a fruit of collaboration between individuals belonging to different communities are important in the sense that they can contribute to the regaining of each other's trust and respect, understanding each other's different but equally painful war-time experiences. This promotes reconciliation. Furthermore, these gatherings create social space for one to learn about what is common and valuing what is unique in each other's cultural heritage, and at last recognizing each other's interdependence (Dharmawardhane, 2013).

The arts, whether it is through music, painting, poetry, prose, song, dance, film, photograph or theatre, can be a vehicle for truth, dialogue, and inter-cultural understanding for communities who speak different languages in nations where communal relations have been battered by conflict and violence. Thus, post-conflict reconciliation efforts must include the emotional and social spaces necessary for victims of conflict and divided community groups to express their feelings and thoughts, in addition to state-led security measures, reconciliatory political processes and policies, a void which culture and the arts can fill.

\section{The Role of Culture in Peace Building and Reconciliation}

In addition to state-sanctioned initiatives such as economic empowerment, reconciliation policies, demobilization and disarmament aid offered by international actors, cultural activities can help in peace-building initiatives and in reconciling former adversarial 
groups. Thus, in addition to being a tool for development and a means to an end; culture and cultural activities can be a means of building peace in the hearts and minds of people and can foster healing on a traumatized community or nation.

\section{Culture and the Promotion of Peace}

After a violent conflict, the norm is that the state and its apparatus move in to tackle problems of peace-building and reconciliation. This can be done through national policies of reconciliation as was the case in Zimbabwe after the 1970s war of liberation (Mashingaidze, 2012) or through a Truth and reconciliation commission as was the case in South Africa at the end of the apartheid era (Tutu, 1995). Others can simply decide to close the books and adopt the policy of amnesia and amnesties. Closing the books was the option taken by post Khmer Rouge Cambodia and Spain after the fall of the Franco regime. However, these approaches have to been able to promote sustainable reconciliation and peace in most of these conflict-ridden zones because the approaches have been largely silent on the history, cultural beliefs, norms, wounds and deeply rooted perceptions of victimized individuals or groups. This is the reason why this article argues for the inclusion of culture and the arts (cultural activities) in the peace-building and reconciliation question.

The cultural beliefs, norms and traditional values of a people can be tapped into through the inclusion of traditional leaders in the peace-building and reconciliation agenda and structures. The incorporation of traditional leaders creates social space for the sharing of experiences, promote dialogue and explore possible cultural approaches as well as activities steeped in a community`s traditional values relevant for peace building, conflict management and conflict resolution. The incorporation of traditional approaches in peace building and reconciliation processes is particularly imperative give that violent tends to create cultural cohesion and to undermine traditional practices. Thus, the inclusion of traditional authorities in the peace-building agenda is quite crucial towards the addressing traditional narratives which can create or fuel violence. In Zimbabwe, the Organ for National Healing, Reconciliation and Integration established following the signing of the Global Political Agreement in 2008 adopted the cultural elements to peace building through a project entitled Traditional Mechanisms, Approaches and Systems for Peace-Building, Conflict Resolution and Resolution (TMASCRR). The project was pursued in partnership with the Zimbabwe Chiefs` Council, giving the peace-building agenda a cultural grounding (UNDP Report, 2014).

According to Cohen, (2009) culture can act as a cushion or catalyst for peace. Culturerelated activities can provide a common space for adversarial groups to meet, communicate and interact. Activities that provide the necessary space include classical music orchestras, soccer practices, games, theatrical productions and painting. Sports such as soccer are often used as an ice breaker to promote dialogue among former enemies, particularly when children are involved. Children will go to a joint practice and play a game together simply because they love soccer and want to play soccer and 
become good soccer players (Cohen, 2014). Soccer is most often used as a medium for trust-building. Children whose identities were defined by their ethnicity before they got to play with their adversaries, gradually come to be identified by their positions in the game, such as goal keeper, forward or defender hence trust and confidence is restored.

Musicians from different cultural and ethnic backgrounds can play together at a national music gala. They appreciate any opportunity to practice, undergo training, and perform in public as a group to come up with a good musical show. Initially, they sometimes find it difficult to play with people from a hostile group, but since they have to communicate with others in order to play in harmony, they soon find themselves cooperating to produce musical harmony and perform better as a group. By sharing music stands and playing together, they come to respect each other for their respective music skills. In Zimbabwe for example, when musicians gather at National galas to commemorate peace or nationalists who worked hard to promote unity in the country such as the "umdhala wethu Nkomo gala, or Muzenda bira" they do not identify themselves as Shonas or Ndebeles or Tongas or as ZANU PF or MDC supporters but as musicians.

Theatrical productions are also an avenue through which local people can express their thoughts, while compelling them to collaborate and communicate. In the process, they learn how other people think, how they persevere, and how they perceive the conflict. This process also allows them to re-identify themselves and others. The advantage of these cultural activities is that they a performed at neutral venues such as a soccer field or stadium or a stage. When the venue for dialogue or cultural activities is outside the conflict area, neither of the adversarial groups have an advantage over the other, placing them on a more equal footing (Dharmawardhane, 2014). Cultural contributions that provide such opportunities enable adversaries to communicate and, thus, gradually see beyond the stereotypical image they have had of the other party throughout the conflict. It should also be noted that although people do not take part in cultural contributions to make peace, their contributions to cultural initiatives do serve as a common language that allows adversaries to communicate. As such cultural contributions offer opportunities for people who once fought each other to re-identify each other, not as enemies, but as someone who shares their passion and interest in cultural activities.

\section{Culture as a Medium of Peace}

Cultural contributions have the potential to act as a medium for building peace in the hearts and minds of local people. Certainly, conflict affects people physically, but it is the psychological wounds that are often the hardest to heal (Cohen, 2009). Physical peace-building may improve the system of government, allow people to participate in elections and promote economic reconstruction. However, should psychological wounds remain, it may not be possible for the adversaries to conduct any substantive peacebuilding activities. Without peace in the hearts and minds of the people, there can be no lasting peace. Thus, it is imperative that communication between the conflicting parties be facilitated by building tolerance, mutual understanding, trust and confidence. 
Attending to identities that have been damaged by war is equally important. Issues surrounding identity play a major part in conflict, and those that have been fractured during the conflict need to be restored in the interests of peace-building. Cultural activities allow individuals to build a new identity by taking part in theatrical activities, music performances and sports. Post-traumatic stress disorder, which can obstruct peace efforts, often can be cured using cultural rituals and rites. Mwandayi (2011) defines a ritual as an action usually prescribed by the traditions of a community or by political laws because of the perceived efficacy of those actions. Rituals are highly symbolic acts that confer transcendental significance and meaning on certain life events or experiences.

Peace-building performances at rituals, music galas or theatre can heal the mind psychologically, emotionally and spiritually. The performance space is energized by mythological, spiritual, historical and other cultural resonances evoked by characters, costumes, music and setting. In Cohen`s opinion, peace-building rituals and ceremonies are powerful events that can be crafted to engage people compellingly, but noncoercively, in the issues that confront their communities. They are laboratories for exploring relationships, memories, questions and meanings, for experimenting with cross-cultural encounters and for discovering what might be possible (Avaruch, 2011). In addition, performances at these peace-building activities provide ways of integrating narratives at the psychological, emotional and physical levels, a necessity in violent contexts where narratives likely have been torn apart.

Avaruch (2011), further asserts that cultural rituals can heal victims, promote reconciliation because they create social space for the remembrance and honoring comrades and loved ones who would have been killed. The opportunity to honor fallen comrades and local community heroes dignifies the suffering and the injuries of the past, while avoiding the traps of traumatization and permanent victim and perpetrator identities. In addition, these rituals or ceremonies helps in building relationships and helping communities to imagine a new future.

Thus, performances of theatre and rituals can capture people's attention, reaching beneath the defensive structures of guilt, shame and rage; to restore capacities for agency and heal relationships; challenge existing assumptions; support expression that is otherwise forbidden (Avaruch, 2011). Furthermore, performances have the potential to bring reluctant adversaries into conversation and propose new ways of framing issues. Even when confronted with the power of violence, economic, political, gender-based and cultural domination, performances challenge and subvert widely accepted patterns of supremacy, fear, exclusion and repression.

\section{Culture and the Prevention of Conflicts from Recurring}

Rubinstein (1992) observed that peace building performances have the potential to support communities to engage with problematic silences and to navigate among apparently conflicting and contradictory imperatives. Whether in the midst of violence and oppression, in their aftermath, or in contexts of social, economic and political 
exclusion; communities are filled with unexpressed and unacknowledged stories of injustice (Rubinstein, 1992). In most cases, individuals, families or communities are flooded with suppressed truths about abuses of power, unexpressed rage and fear, unmoored losses, unresolved conflicts, unspoken remorse and unreconciled relationships, peace-building performances are uniquely well-suited to engage these silences. Theatre and ritual express suppressed and repressed ideas, feelings, relationships, and yearnings for the future. By cultivating, nourishing and restoring capacities for communication and building relationships a whole. Peace building performances in post-conflict areas can support communities to grapple with complexities such as the need to resist violent assaults, cultural impositions and other infringements on individual and collective agency - without unnecessarily fueling more violence through one's reactions, and without becoming passive or self-destructive in the face of one's apparent powerlessness.

\section{The Educative Role of Culture on Conflicts and Violence}

Cultural contributions can be effective mediums for the empowerment of local people and prevent conflicts from recurring, as happens all too often. While economic development is essential for the alleviation of poverty and to empower local people, true empowerment depends on having a school education and being taught about matters of everyday life. Thus, cultural activities can be combined with formal education to teach about unity, peace effects of conflict and violence on individuals, families and the community. Cultural activities can be used to foster a culture of peace in children from primary level right up to university or college levels. Education, particularly that which targets young people is critical towards internalizing values of non-violence and promoting practices of peaceful settlements of disputes (Cohen, 2009).

Creative ways of teaching, using radio programs, theatre productions, and films about the importance of sending children to school can play an important role in peace-building. Such projects combine the pleasure of cultural activities with education. Thus, when straightforward education faces resistance from the people, cultural contributions are better placed to deliver messages. Moreover, cultural productions enable people to express themselves and tell stories, thereby validating their own experiences.

Cohen further observed that among all the cultural contributions, producing literary works is perhaps the most private medium. When authors write about their memories of war, people can, in their own private space, read about how war was perceived by different groups. This helps individuals to squarely confront their past, rather than block it off, and so overcome war memories. Writing enables people to express feelings that might otherwise be difficult to articulate. Writing and poetry can also foster peacebuilding and reconciliation. "Peace literature", literature written by local writers on themes of peace and inter-ethnic harmony, should be a part of peace education incorporated in education curricula from kindergarten through university. 
International literature which carries the message of peace can also be included in syllabi (appropriate to grade level). Translations of great works by writers from different ethnic communities should be included in literature classes and the state must sponsor the translations of peace literature. Special emphasis should be placed on poetry in writing and literature classes to revive the proud tradition of writing poetry. Writing, literature, art, and performing arts classes can thus be taught in school and universities in the spirit of peace and in celebration of the rich cultural diversity of a given country. It is imperative that teachers and lecturers are trained and supervised in this regard.

Painting is another way of expressing oneself and healing the scars and traumas of war. It also enables peace-builders to discover what traumas people, particularly children, women and the youth have experienced (Rubinstein, 2008). Children asked to paint something depicting the past, present or future often cannot draw their past and, at best, will use black crayon to present it. Women or the youth, asked to paint a conflict incident on a big sheet of paper as a group, will paint a different picture from the one painted by children as they see or perceive it in the eye of their minds. International actors sometimes collect paintings produced by children in conflict areas and exhibit those in other countries or show them to groups of children overseas, asking them to draw the impressions they get from seeing the paintings from the conflict areas. Such exchanges allow children in areas of conflict to learn both that there is another world out there, and something about the children who live there, which enables them to relativize conflicts

Paintings and drawings help in communicating our inner thoughts and feelings, and their therapeutic effect in the rehabilitation process has been recognized. Similarly, art workshops can also be held for adults of conflict-affected areas, which can be a space for former combatants and members of the community to interact. This allows working together and strengthening unity and social cohesion creating space for peace building and reconciliation. Sculpture and arts parks and community murals can also be created to commemorate nationally-celebrated leaders and social activists who have greatly contributed to the cause of peace democracy, and justice, often sacrificing their lives the likes of Martin Luther King, Nelson Mandela, Desmond Tutu, and Joshua Nkomo, In Zimbabwe for example, a metal man -sized statue of Joshua Nkomo is found at the city center of Bulawayo as a constant reminder of his efforts towards national unity and against tribalism in the country.

A national exhibition can be convened to exhibit, side-by-side, the paintings and drawings on the theme of reconciliation of the different groups of conflict-affected individuals, school children, university students of art, professional and reputed local artists. Such a symposium where all contributors would have a 'voice' would enable participants and viewers of the public alike to leave with a 'collective' message, by understanding each other's point of view, where we agree and disagree, as well as our common hopes and dreams. Art exhibitions have been held by various groups in many conflict-affected quarters of the world. For example, in Sudan, "Art of Reconciliation" was the first art exhibition after the end of Sudan's civil war in 2005 which claimed two 
million lives, and South Africa's Truth and Reconciliation Commission inspired artist Madelaine Georgette to embark on a personal path for inner reconciliation and exhibit many collections on the theme of reconciliation (Cohen, 2009). In Zimbabwe ONHRI made exhibitions on their works on reconciliation at the Zimbabwe International Trade Fair in 2012 and another one at the Bindura Career Guidance and Book Fair Expo in the same year (ONHRI Report, 2015).

\section{Culture for Promoting the Culture of Peace}

Culture is an integral component in the promotion of a culture of peace. The United Nations defines the culture of peace as "a set of values, attitude, modes of behavior and ways of life that reject violence and prevent by tackling the root causes to solve problems through dialogue and negotiation among individuals, groups and nations (United Nations General, 1997) Culture and cultural activities such as sports, art, education, music and theatre together with processes of socio-economic development can be harnessed in the promotion of the culture of peace. The culture of peace can be promoted by engaging with the arts community. Cultural events are also important forums for exploring the often challenging and contested issues of reconciliation, national healing and peacebuilding. Thus, governments can focus on a wide range of local opportunities provided by artist and cultural events which will bring people together from different backgrounds, in order to relay messages of peace and reconciliation.

In Zimbabwe, the government through the Ministry of Education, Sports and Culture used the arts to promote the culture of peace in primary and secondary schools. A National, Poetry and Essay competition was held with over a thousand schools participating. Five thousand students participated in this national competition. Winners of the National Art, Poetry and Essay Competition were announced during the commemoration of the United Nations International Day of Peace on 21 September 2012 (ONHRI Report, 2015). In this case, cultural activities provided a platform for the younger generation in Zimbabwe to participate and to be recognized for their unique and important experiences in strengthening peace and reconciliation initiatives. In addition, through the competition, the importance of understanding and incorporating the perspectives of the youth in processes of conceptualizing peace building and reconciliation was demonstrated. In addition, by targeting the education sector in processes of institutionalizing a culture of peace, the approach demonstrated immense understanding of the transformative role of education.

\section{Limitations of culture towards Peace building and reconciliation.}

While cultural contributions have the potential to foster peace in post- conflict zones, they can also place severe limitations on peace-building activities. First and foremost, cultural contributions are affected by political situations and while such contributions may thwart confrontation, a sudden change in the political environment may cause 
cultural activities to be suspended. The safety of actors conducting cultural contributions is often threatened, even in post-conflict situations, as there often remain armed skirmishes.

Cultural contributions are expensive and so they are mostly funded by international organizations. As such they tend to be transient in nature, and may not have a lasting impact in post- conflict zones. Cultural contributions from outside can be conducted for a certain length of time, but cannot continue forever. So, local actors such as governments, commissions and civil society groups must find a way of enabling local people to develop ownership of cultural activities. This could be done by encouraging and promoting the arts industry at home or in local communities, the teaching of arts, local theatre productions and performances on local arts festivals, national commemoration events such as Independence celebrations, Heroes day celebrations or national unity galas.

Immediately after a conflict, people tend to need food and money, rather than cultural events. Thus, unless we understand local needs and provide local people with a combination of peace-related elements, cultural contributions for peace-building may not be accepted by the local people or even be effective. Furthermore, when conducting peace-building efforts to assuage the pain afflicting the hearts and minds of local people, the actors must grapple with sensitive psychological issues such as identity. If the approach taken is not appropriate to the particular local setting, cultural contributions can even be counterproductive

\section{Conclusion}

Cultural contributions for fostering peace comprise a delicate and complex challenge to governments and other actors in the peace-building and reconciliation field. However, there is no denying that these are potential, and sometimes essential, factors in effective peace-building in 21 st-century conflicts. Since there are numerous civil wars, rather than inter-state conflicts, many people find themselves having to live in the same, or a neighboring, community together with those who until a short time before had been their enemies. Thus, the cultural aspect of local communities cannot be ignored. Culture is no longer a luxury, and should be confronted and incorporated in the peace-building agenda, should we work for lasting peace and to reduce the recurrence of conflicts.

\section{References}

Avaruch, K. (2011). Context and pretext: Essays on culture, identity, power and practice. Boulder, CO: Paradigm Publishers.

Fernea, E. W. and. Hocking M.E. (eds.) (1992). The struggle for peace: Israelis and Palestinians. Austin, TX: University of Texas Press. 
Falola, T. (1998). Violence in Nigeria: The crisis of religious politics and secular ideologies, New York: University of Rochester Press.

Galtung, J. (1996). Peace by peaceful means: Peace, conflict, development and civilization, London: Sage Publications.

Gunaratna, R. (2012). "Reconciliation through education”, National Conference on the Role of Education in Reconciliation, Lakshman Kadirgamar Institute for International Relations and Strategic Studies (LKIIRSS), Colombo.

Kriesberg, L. (2004). Comparing reconciliation actions within and between countries, In Yakov Bar-Siman-Tov, (ed.) From conflict resolution to reconciliation, Oxford: Oxford University Press.

Lederach, J. P. (1997). Building peace: sustainable peace in divided societies, Washington DC: United States Institute for Peace.

Lederach, J. P. (1995). Preparing for peace: conflict transformation across cultures. New York: Syracuse University Press.

Lederach, J. P. (2003). Little book of conflict transformation: intercourse. PA: Good Books.

Mark, I. (2007). Reconciliation: Bridging theory to practice: a framework for practitioner, The Hague, Centre for Justice and Reconciliation.

Mashingaidze, I. (2012). Zimbabwe`s elusive national healing and reconciliation processes: from independence to the inclusive government, 1980-2009, Conflict Trends, Issue, ACCORD, Durban South Africa.

Meagher, K. (2004). Identity economics: Informal manufacturing and social networks in Southeastern Nigeria, (Unpublished D.Phil. Thesis), Oxford: University of Oxford.

Murithi, T. (2006) African approaches to building peace and solidarity, African Journal on Conflict Resolution, 6 (2), pp. 80-120.

Mwandayi, C. (2011). Death and after-life rituals in the eyes of the Shona. University of Bamberg Press.

Rubinstein, R. A. (2008). Peacekeeping under fire: Culture and intervention. Boulder, CO: Paradigm Publishers.

Tutu, D. (1995). No Future without forgiveness. Michigan: Doubleday.

UNDP Report, Strengthening the National Peace and Reconciliation Infrastructure in Zimbabwe: Key Milestones of the Organ for National Healing, Reconciliation and Integration (ONHRI) 2009-2014, 2015.

United Nations General UN/A/RES/53/343: Declaration and Programme of Acting on the Culture of Peace, 1997. 
Zartman, I. W. (ed.) (2000) Traditional cures for modern conflicts: African conflict "medicine," Boulder, CO: Lynne Rienner Publishers.

Zelizer, C. and Rubinstein, R. A. (eds.) (2000). Building peace: Practical reflections from the field. Sterling, V.A.: Kumarian Press.

\section{Internet Sources}

Dharmawardhane, I. (2013). Sri Lanka: The role of the arts and culture in reconciliation: analysis, available at http://www.eurasiareview.com/23042012-sri-lanka-therole-of-arts-and-culture-in-reconciliation-analysis/, accessed 7 January 2017.

Hutt, J. and Hosking, B. (2004). "Playback Theatre: A creative resource for reconciliation", recasting reconciliation through culture and the arts: A Virtual Collection, International Center for Ethics, Justice and Public Life, Brandeis University, at http://www.brandeis.edu/ethics/peacebuildingarts/pdfs/peacebuildingarts/Bev Je nny_final_ALDEdit.pdf , accessed April 15, 2012.

Selibe, D. (2004). "Art, ubuntu, and reconciliation", International Center for Ethics, Justice and Public Life, Brandeis University at http://www.brandeis.edu/ethics/peacebuildingarts/recasting/gallery/howdeep/ind ex.html accessed April 15, 2012.

Shah, A. (2014). Conflicts in Africa. Available at http://www.perfomingtransformation.blogspot.com/2012/10/plethora-ofinitiatives-has-been-and-is.htm, accessed 7 January 2017. 